\title{
Alteration of lung diffusion capacity in IgA nephropathy
}

Sophie Ravilly, Michèle Chaussain, Jean-Luc Iniguez, Agnès Lenhert, Gabriel Kalifa, Philippe Brun, Patrick Niaudet, Dominique Gendrel

\begin{abstract}
Objective-To establish whether changes of lung transfer for carbon monoxide (TLCO) are related to the phase of IgA nephropathy.

Methods-Respiratory function was tested in 12 children with IgA nephropathy assessed by percutaneous renal biopsy. This was done during acute exacerbations or haematuria-free phases of the disease.

Results-TLCO was low in 12/13 measurements made in the haematuric phase of IgA nephropathy or during the month following gross haematuria (mean TLCO $64 \%$ of expected values). Lung volumes and blood gas values were normal and only minor radiological signs of interstitial lung involvement were observed in 11/12 patients. When respiratory tests were performed more than three months after gross haematuria, TLCO was low in 4/9 patients, with no relation to the significance of residual proteinuria or severity of findings at renal biopsy. There was a significant difference between tests performed when haematuria was present or recent and those performed more than three months after an episode of gross haematuria $(\mathbf{p}<0 \cdot 01)$.

Conclusions-The decrease of TLCO in the acute phases of the disease is probably related to alterations of the lung alveolarcapillary membrane by immune complexes containing IgA. This non-invasive technique, easy to perform and repeat, could be of value in the diagnosis of $\operatorname{IgA}$ nephropathy in haematuric children.

(Arch Dis Child 1996; 74: 236-238)
\end{abstract}

Keywords: IgA nephropathy, Berger's disease, TLCO, haematuria.

$M$ Chaussain

$\mathrm{J}$-L Iniguez

G Kalifa

D Gendrel

Department of Paediatrics, Hôpital Necker-Enfants

Malades, Paris, France

A Lenhert

P Niaudet

Department of

Paediatrics, Hôpital

Robert Debré, Paris,

France

P Brun

Correspondence to:
Dr Dominique Gendrel, c/o

Dr Dominique Gendrel,
Hôpital Saint Vincent de

Paul, 82 Av Denfert-

Rochereau, 75014 Paris,

France.

Accepted 14 November 1995 (TLCO) in the early stages of the disease and the persistence of this abnormality in children with Henoch-Schönlein purpura nephritis. ${ }^{34}$ IgA immune complexes are present in both
IgA nephropathy and Henoch-Schönlein purpura, and may be involved in the immune mechanisms leading to TLCO abnormalities observed in Henoch-Schönlein purpura. To test this hypothesis we measured TLCO in children with IgA nephropathy during both acute exacerbations and haematuria-free phases of the disease. The aim of the study was to establish whether changes of TLCO were related to the phase of IgA nephropathy.

\section{Methods}

Twelve patients ( 11 boys and one girl) aged $7 \cdot 1$ to $17 \cdot 2$ years (mean 12 years) were prospectively enrolled from January 1990 to June 1993. All had recurrent macroscopic haematuria and a diagnosis of IgA nephropathy made after percutaneous renal biopsy. None had urinary tract infection or malformation, and abdominal ultrasonography was normal in all cases. No patient had known chronic or acute lung disease, clinical or laboratory symptoms of systemic lupus erythematosus or a history of Henoch-Schönlein purpura.

We measured proteinuria and blood haemoglobin at the time of all TLCO measurements. A chest $x$ ray was performed to rule out pneumonia. Respiratory tests included vital capacity and functional residual capacity (FRC) determined by helium dilution technique, blood gas measurements $\left(\mathrm{PaO}_{2}\right.$ and $\left.\mathrm{PaCO}_{2}\right)$ on arterialised capillary blood collected from the ear lobe, and TLCO. We measured TLCO by a previously described method. ${ }^{56}$ Briefly, under resting conditions during steady state, alveolar gas was sampled and carbon monoxide concentration measured. This method has been shown to be reliable, with less than a $5 \%$ difference in two consecutive measurements. ${ }^{357}$ The results are expressed as a percentage of previously reported normal values for gender and height. ${ }^{5}$ We also calculated the TLCO/ FRC ratio, as a percentage of predicted value, to avoid low values of TLCO caused by a restrictive disorder. TLCO and TLCO/FRC were considered abnormally low if they were below $90 \%$ of the predicted value. 56

All chest $x$ rays were examined by the same radiologist, who was blind to the final diagnosis, pathological findings, and results of respiratory tests. The radiological findings were scaled as follows: 0 , normal; +1 , blurring of pulmonary vasculature.

The results were compared by means of the unpaired two tailed $t$ test. For each patient only the first measurement was used for the mean calculation.

The board of the department of paediatrics

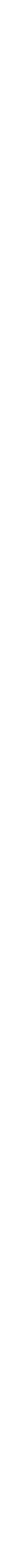


Results of measurements of TLCO in 12 patients with IgA nephropathy and in two patients with Alport's syndrome

\begin{tabular}{|c|c|c|c|c|c|c|c|}
\hline & $\begin{array}{l}\text { Age } \\
\text { (years) }\end{array}$ & $\begin{array}{l}\text { Last } \\
\text { haematuria }\end{array}$ & $\begin{array}{l}\text { Proteinuria } \\
(g / 24 h)\end{array}$ & $\begin{array}{l}\text { TLCO } \\
\text { (\% normal) }\end{array}$ & $\begin{array}{l}\text { TLCO/FRC } \\
(\% \text { normal })\end{array}$ & $\begin{array}{l}\text { Renal } \\
\text { biopsy }\end{array}$ & $\begin{array}{l}\text { Chest } \\
\mathrm{x} \text { ray }\end{array}$ \\
\hline $1 / M$ & $\begin{array}{l}8 \cdot 6 \\
9.5\end{array}$ & Present & 1.5 & 82 & 58 & FSP & \pm \\
\hline $2 / M$ & $14 \cdot 5$ & 4 months & $0 \cdot 4$ & $\begin{array}{r}107 \\
64\end{array}$ & 84 & MP & 0 \\
\hline & 15.6 & $>1$ year & 0 & $\begin{array}{l}04 \\
99\end{array}$ & $\begin{array}{l}35 \\
83\end{array}$ & $\mathbf{M P}$ & 0 \\
\hline $3 / M$ & $15 \cdot 1$ & 1 month & 0 & 75 & 62 & FSP & \pm \\
\hline & $16 \cdot 2$ & 1 month & 0 & 121 & 108 & & ND \\
\hline $4 / M$ & $9 \cdot \overline{8}$ & Present & 0.5 & 49 & 51 & DP & \pm \\
\hline $5 / M$ & $\begin{array}{l}15 \cdot 0 \\
16 \cdot 3\end{array}$ & $\begin{array}{l}1 \text { month } \\
10 \text { months }\end{array}$ & $\begin{array}{l}1.5 \\
1.5\end{array}$ & $\begin{array}{r}64 \\
130\end{array}$ & $\begin{array}{l}55 \\
99\end{array}$ & FSP & \pm \\
\hline $6 / \mathrm{M}$ & $13 \cdot 0$ & 1 month & 0 & 73 & 66 & MP & \pm \\
\hline 7/M & $\begin{array}{l}13 \cdot 3 \\
14 \cdot 4\end{array}$ & 11 months & $1 \cdot 2$ & $\begin{array}{r}81 \\
107\end{array}$ & $\begin{array}{r}64 \\
104\end{array}$ & FSP & \pm \\
\hline $8 / \mathrm{M}$ & $10 \cdot 3$ & Present & $0 \cdot 2$ & 49 & 49 & MP & + \\
\hline & $10 \cdot 6$ & Present & 0.1 & 51 & 52 & & + \\
\hline & $10 \cdot 9$ & Present & 0 & 59 & 52 & & ND \\
\hline & $11 \cdot 8$ & 4 months & 0 & 84 & 112 & & ND \\
\hline & $12 \cdot 9$ & Present & $0 \cdot 1$ & 71 & 77 & & + \\
\hline 9/M & $15 \cdot 7$ & 1.5 years & 1.5 & 62 & 46 & DP & + \\
\hline & $17 \cdot 2$ & 3 years & $1 \cdot 2$ & 138 & 105 & & 0 \\
\hline $10 / M$ & $13 \cdot 7$ & 1 month & 0.5 & 58 & 69 & FSP & \pm \\
\hline $11 / M$ & $10 \cdot 1$ & 4 months & $2 \cdot 5$ & 93 & 95 & $\mathrm{DP}$ & ND \\
\hline $12 / \mathrm{F}$ & $7 \cdot 1$ & 1 month & 0 & 77 & 63 & MP & \pm \\
\hline $13 / \mathrm{F}$ & $9 \cdot 3$ & 1 month & 0.3 & 101 & 113 & Alport's & $\overline{0}$ \\
\hline $14 / M$ & $3 \cdot 6$ & Present & 0.2 & 106 & 109 & Alport's & 0 \\
\hline
\end{tabular}

$0=$ normal; $\pm=$ slight blurring of pulmonary vasculature; $+=$ blurring of pulmonary vasculature; $\%$ normal $=$ percentage of predicted value; $\mathrm{ND}=$ not done; $\mathrm{FSP}=$ focal and segmental proliferation; $M G N=$ mesangiopathic glomerulonephritis; $D P=$ diffuse proliferation.

of Saint Vincent de Paul hospital approved this non-invasive study.

\section{Results}

The results are reported in table 1 . All patients had biopsy proven IgA nephropathy. By light microscopy, four patients had mesangiopathic glomerulonephritis, five showed segmental and focal glomerulonephritis, and the remaining two had an endoextracapillary glomerulonephritis. TLCO was measured 22 times in the 12 patients. Measurements were performed 13 times during an acute phase of gross haematuria or within the month following this episode. The nine other tests were performed more than three months after an episode of gross haematuria (four months to three years). At the same time, proteinuria, ranging from 0.4 to $2.5 \mathrm{~g} / \mathrm{d}$, was present in seven of these nine patients. Seven patients had repeated tests, but only four had paired acute and convalescent studies. The patients received no treatment except patient No 11 , who received prednisone $(20 \mathrm{mg} / \mathrm{d})$ for nephrotic syndrome. Serum IgA values were above the normal range in nine of the 12 patients. Haemoglobin was normal in all patients and did not change significantly when they were free from haematuria.

We found no pulmonary restrictive syndrome. Lung volumes were normal or slightly high: mean vital capacity was $103 \%$ of predicted (range: $80 \%$ to $133 \%$ ), and mean FRC was $114 \%$ of predicted (range $95 \%$ to $138 \%$ ). Mean $\mathrm{PaO}_{2}$ and $\mathrm{PaCO}_{2}$ were $12 \cdot 18 \mathrm{kPa}$ (range 11.57 to 13.39 ) and $5.02 \mathrm{kPa}$ (range 3.90 to $5 \cdot 46)$ respectively.

TLCO or TLCO/FRC measured in the haematuric phase of the disease or during the following month was low in $12 / 13$ tests. Mean TLCO and TLCO/FRC were 68 (SD14)\% (range 49 to 121) and 62 (15)\% (49 to 108) of predicted values. A normal value of TLCO measured one month after a haematuric episode was found in patient 3 , in whom a low value had been detected in the preceding year just after gross haematuria. Radiological signs of interstitial lung involvement were minor but generally related to the decrease of TLCO, without evidence of other pulmonary abnormality.

We considered TLCO or TLCO/FRC to be within the normal range in six of nine patients tested more than three months after an episode of gross haematuria: mean TLCO and TLCO/FRC were respectively 101 (25)\% and $87(22) \%$ of predicted value (figure). In patients $1,2,3,5$, and 8 , in whom low values were found when haematuria was present or recent (within one month of tests), TLCO or TLCO/FRC reached the normal range during the intervals between the haematuric episodes, even when proteinuria persisted. The magnitude of impairment of lung diffusion was not related to severity of the glomerular lesions associated with IgA deposits, to the level of serum IgA, or to the degree of proteinuria.

Additionally, two patients with isolated gross haematuria initially considered to have IgA nephropathy were finally diagnosed as Alport syndrome after renal biopsy (absence of IgA deposits, thin basement membrane nephropathy by electronic microscopy, and hearing loss). Pulmonary function tests were performed during an episode of gross haematuria. Their lung volumes, chest $x$ ray, blood gases, and lung diffusion were normal: TLCO was respectively $101 \%$ and $106 \%$ of predicted values, and TLCO/FRC was $113 \%$ and $109 \%$.
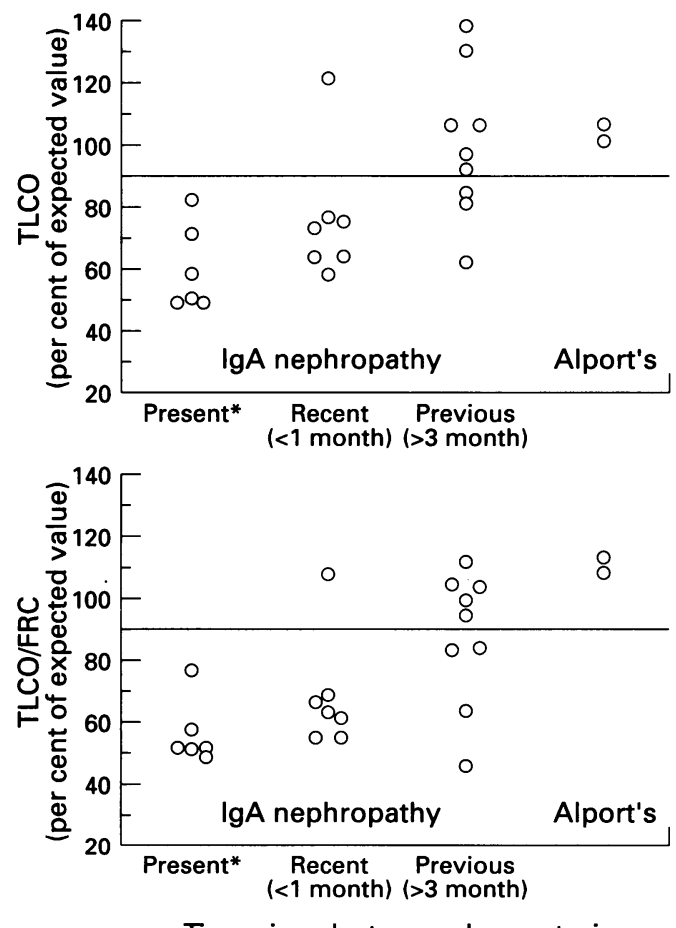

Time since last gross haematuria

TLCO (lung transfer for carbon monoxide) and the TLCO to FRC (functional residual capacity) ratio at different phases of IgA nephropathy and in two haematuric patients with Alport's syndrome. (Values considered to be low if below $90 \%$ of predicted.) There is a significant difference between the tests performed during the presence of gross haematuria and those performed more than three months after an episode of gross haematuria $\left({ }^{\star} p<0.01\right)$. 


\section{Discussion}

We recently reported impairment of TLCO in children with Henoch-Schönlein purpura, but this has not been described before in children with IgA nephropathy. Although we did not obtain paired acute and convalescent studies in eight patients, we found that TLCO was low in the early stages of Henoch-Schönlein purpura, became normal after disappearance of the clinical symptoms, and remained low when Henoch-Schönlein purpura nephritis persisted for months or years after the initial skin rash. Thus normal TLCO appeared to be associated with remission and it fell when HenochSchönlein purpura relapsed. ${ }^{34}$ In the present study, all patients with IgA nephropathy tested during or just after a bout of macroscopic haematuria had low values of TLCO. One TLCO was in the normal range one month after a haematuric episode. However, TLCO was low when measured in the same patient the year before, one month after gross haematuria.

Acute upper respiratory infections often precede clinical exacerbation of IgA nephropathy. Chronic pulmonary diseases have rarely been reported with IgA nephropathy, although pulmonary fibrosis, chronic asthma, and haemosiderosis have been described in adult patients. ${ }^{8}$ Children with interstitial lung disease, such as sarcoidosis, haemosiderosis, hypersensitivity pneumonitis, histiocytosis $\mathrm{X}$, and malignancies with interstitial pneumonia, present with markedly abnormal chest $x$ ray and decreased TLCO, with hypoxaemia and low lung volumes secondary to pulmonary fibrosis. ${ }^{7}$ Our results in IgA nephropathy show minimal radiological interstitial lesions. As in Henoch-Schönlein purpura, diffusion capacity measured by TLCO was the sole impaired pulmonary function.

IgA nephropathy and Henoch-Schönlein purpura have similar pathological findings, with mesangial IgA deposits. ${ }^{9} 10$ Overproduction of $\operatorname{IgA}$, and circulating immune complexes containing IgA are seen in both diseases. ${ }^{21-13}$ IgA deposits are also found in unaffected skin of patients with HenochSchönlein purpura or IgA nephropathy, showing that immune deposits may be found in apparently normal tissues in the two diseases. ${ }^{14}$ Sera of patients with IgA nephropathy and Henoch-Schönlein purpura nephritis contain circulating antibodies that can bind to an antigen of mesangial cells in culture. These antibodies can be detected in the haematuric phase of IgA nephropathy or acute HenochSchönlein purpura and disappear after partial or complete remission. ${ }^{1516}$ Thus impairment of TLCO in both diseases is possibly related to the deposition of IgA containing immune complexes or other antibodies on the vascular side of the alveolar-capillary membrane during the active phase. During periods of apparent clinical remission, TLCO is in the normal range in both diseases. This suggests it is in parallel with the disappearance of the immunological abnormalities observed in the acute phase.
Normalisation of TLCO, observed after the haematuric phase, was not related to the level of IgA, the severity or extent of glomerular changes, or the residual proteinuria in IgA nephropathy. Low TLCO therefore appears to be a result of disease activity where there is rash or haematuria, but may be normal between acute episodes of both diseases, even when there are sequelae of glomerular injury. There is a significant difference between the tests performed when haematuria is present and those performed more than three months after an episode of gross haematuria: $p<0.01$ (present $v$ previous). We tested only two patients with Alport's syndrome, in whom the diffusion capacity performed during an episode of macroscopic haematuria was normal.

A low TLCO value, as in the acute phase of Henoch-Schönlein purpura, seems to be a major feature during episodes of macroscopic haematuria in IgA nephropathy. This noninvasive technique, easy to perform and repeat, could be of great help for the differential diagnosis of IgA nephropathy in children with haematuria. However, further studies are needed in children with haematuria from other glomerular diseases to demonstrate the specificity of the test.

Supported by grant No 922804 from Recherche Clinique APHP, Paris, France

1 Meadow SR, Scott DG. Berger disease: Henoch-Schönlein syndrome without the rash? f Pediatr 1985; 106: 27-32.

2 Clarkson AR. Henoch-Schönlein purpura and IgA nephropathy : to separate or unify ? In: Clarkson AR ed. IgA nephropathy Boston: Martinus Nijhoff, 1987: 39-46.

3 Chaussain M, de Boissieu D, Kalifa G, et al. Impairment of lung diffusion capacity in Schönlein-Henoch purpura. $f$ Pediatr 1992; 121: 12-16.

4 Gendrel D, Chaussain M. Anomalies de la diffusion pulmonaire au cours du purpura rhumatoïde. In: Textbok of fournées Parisienne de Pédiatrie. Paris: Flammarion, 1992: 215-20.

5 Chaussain M, Denjean A, Lebeau C, De Lattre J, Badoual J. Lung transfer factor for $\mathrm{CO}$ in normal children by a steady-state method. Bull Eur Physiopath Resp 1982; 18: 411-7.

6 Koch G, Gaultier C, Boule M, Chaussain M. Transfer factor (diffusing capacity): steady-state method. Eur Resp Ұ 1989; 2 (suppl 4): 164-6S.

7 Gaultier C, Chaussain M, Boulé M, et al. Lung function in intersitial lung diseases in children. Bull Eur Physiopath Resp 1980; 16: 57-66.

8 Mustonen J, Pasternak A. Associated diseases in IgA nephropathy. In: Clarkson AR, ed. IgA nephropathy. Boston: Martinus Niihoff, 1987: 47-65.

9 Levy M, Gonzales-Burchard G, Broyer M, et al. Berger's disease in children. Medicine 1985; 64: 157-80.

10 Habib R, Niaudet P. Renal involvement in SchönleinHenoch purpura. In: Tischer CC, Brennei BM, eds. Renal pathology with clinical and functional correlation. Philadelphia: JB Lippincott, 1989: 409-33.

1 Kauffmann RH, Herrmann WA, Meyer CJLM, et al. Circulating IgA immune complexes in Schönlein-Henoch purpura : a longitudinal study of their relationship to disease activity. Am $\mathcal{F}$ Med. 1980; 68: 859-66.

12 Kameda A, Yoshikawa N, Shiozawa S, et al. Lymphocyte subpopulations and functions in childhood IgA nephropathy. Nephron 1991; 59: 546-51.

13 Jennette JC, Wieslander J, Tuttle R, Falk RJ, and the Glomerular Disease Collaborative Network. Serum IgAfibronectin aggregates in patients with IgA nephropathy $f$ Kidanostic value and pathogenic implications. Am $\mathcal{F}$ Kidney Dis 1991; 18:

14 Thompson AJ, Chan YL, Woodroffe AJ, Clarkson AR, Seymour AE. Vascular IgA deposits in clinically normal skin of patients with renal disease. Pathology 1980; 12: skin of pati $407-13$.

15 O'Donoghue DJ, Darvill A, Ballardie FW. Mesangial cell autoantigens in immunoglobulin A nephropathy and Henoch-Schönlein purpura. F Clin Invest 1991; 88: 1522-30.

16 Linne T, Berg U, Bohman S, Sigström L. Course and longterm outcome of idiopathic IgA nephropathy in children. Pediatr Nephrol 1991; 5: 383-6. 